\title{
Algumas consideraçōes sobre Simuliidae (Diptera : Nematocera)
}

\author{
V. Py-Daniei $\left({ }^{*}\right)$
}

\section{Resumo}

Com base em observações do abdome pupal de algumas espécies neotropicais de Simuliini e Prosimuliini, sem o uso do $\mathrm{KOH}$ (Hidróxido de Potássio) como agente "limpador-clarificante", sâo propostas algumas alterações nas definições apresentadas por Crosskey (1969) e por Wygodzinsky \& Coscarón (1973) para estas tribos: Simuliini com áreas membranosas estriadas longitudinais medianas nos esternitos V, VI-VII e algumas vezes também no VIII; Prosimuliini somente apresentando áreas estriadas membranosas longitudinais, medianamente, nos esternitos VI-VII e algumas vezes também no VIII.

\section{INTRODUÇÃo}

Uma das dificuldades de detinir as tribos Prosimuliini Enderlein e Simuliini Newman vem da falta de conhecimentos básicos sobre a biologia da maioria das espécies, como tam bém do pequeno número de estudos pormenorizados sobre a morfologia das mesmas, estando estes conhecimentos mais aprofundados, apenas, nas espécies de interesse médico.

Contribui também para esta desinformação, o uso de diferentes produtos químicos na preparação de espécimens para observações microscópicas.

A aplicação destes diferentes produtos faz com que os insetos, ou parte destes, se comportem diversamente : contração-expansão deformando as peças, perda ou não de setas, diminuição ou não da esclerotização de certas partes e podendo dar formato curvo à setas naturalmente lineares e longas.

$\mathrm{O}$ método de colocar o inseto em uma mis. tura de $\mathrm{KOH}$ (Hidróxido de Potássio) e água, e levar este conjunto a um aquecimento, é impróprio para os adultos, pupas e larvas.

Nos adultos as escamas se desprendem com muita facilidade, fazendo com que apareçam algumas espécies descritas sem apresentarem tais escamas (p. ex. : escamas das per- nas), mas que existem realmente. Nas larvas, faz com que setas e/ou espinhos que estas possam apresentar ao longo do corpo tornemse tão transparentes que muitas vezes passam desapercebidos. Nas pupas, faz com que pequenas setas localizadas na parte membranosa inter-tergitos e/ou inter-esternitos fiquem pouco evidenciadas; proporcionando também o desaparecimento do contraste entre estruturas esclerotizadas e membranosas, levando ac observador falsas imagens.

Baseado nestas observações, venho propor que o uso de " $\mathrm{KOH}$-quente" fique restrito para as observações rápidas, nas identificações de campo, e que para as descrições de espécies e observações mais pormenorizadas os espécimes sejam colocados em uma mistura de $\mathrm{KOH}$ e água, sob temperatura normal (ambiente), por um período entre 12 e 24 horas e em concentrações de $\mathrm{KOH}$ não inferiores a $10 \%$.

PUPA

O abdome pupal, após ter sido passado peio $\mathrm{KOH}$, cortado ao longo de uma das suas laterais e distendido para observação dos tergitos, esternitos e região pleural, quando pertence a formas que apresentam, naturalmente. fraca esclerotização abdominal ( $p$. ex. : Simuliini), não demonstram o contraste necessário para observar-se certas estruturas ali existentes.

Em observações feitas sem o uso do $\mathrm{KOH}$, em diferentes espécies do gênero Simulium. constatei a presença de áreas membranosas estriadas medianas longitudinais nos esternitos V, VI-VII e algumas vezes no VIII. O que até o presente, na literatura consultada, é dado somente para Prosimuliini (esternitos VI-VII e algumas vezes o VIII com áreas membranosas estriadas medianas longitudinais).

(") - Instituto Nacional de Pesquisas da Amazônia, Manaus: 
Nota-se entăo a grande influência do $\mathrm{KOH}$ no mascaramento de estruturas. Sem o uso deste, também se observa que os ganchos mais externos dos esternitos VI-VII na realidade não pertencem as placas esternais, mas estão localizados nas membranas e separados destas placas esternais por áreas membranosas estriadas longitudinais. Finalmente, a área esclerotizada circulo-espiracular (laterotergito seg. Snodgrass, 1935) pode ser também mascarada. Esta apresenta uma fraca esclerotização na maioria das espécies de Simuliini observada, e com a passagem pelo $\mathrm{KOH}$ torna-se praticamente indiferenciável da membrana que a circunda. Estes laterotergitos podem ser utilizados para ajudar na separação de espécies, dependendo do maior ou menor desenvolvimento das áreas esclerotizadas como também de suas associações com os espiráculos.

O corte do abdome pupal, lateralmente, em sua longitude, facilita muito a limpeza do seu interior (por meio de um estilete), sendo desnecessária a utilização do $\mathrm{KOH}$.

Crosskey (1969) ao apresentar as definições para as tribos Prosimuliini e Simuliini, como também na chave para os gêneros de Simuliidae da África e suas ilhas, entre vários outros caracteres, baseia-se na presença ou ausência de áreas semimembranosas estriadas medianas longitudinais na região ventral das pupas.

Na referida chave de identificação dos gêneros de Simuliidae da África e suas ilhas, Crosskey apresenta :

$$
\begin{aligned}
& \text { "1. } \ldots . . . . . . . . . \text { Sides of abdo- } \\
& \text { men often with discretely formed } \\
& \text { pleurites. Mid venter of segments } \\
& 6 \text { and } 7 \text { (sometimes also } 8 \text { ) with } \\
& \text { semi-membranous longitudinally } \\
& \text { striate areas dividing the sternal } \\
& \text { plates. - Prosimulium. } \\
& \text { out pleurites. Mid venter of seg- } \\
& \text { ments } 6-8 \text { without conspicuos lon- } \\
& \text { gitudinally striate areas ....... } \\
& \text { (Metacnephia, Afrosimulium, Si } \\
& \text { mulium)". }
\end{aligned}
$$

Sendo o gênero Prosimulium o único representante de Prosimuliini, e os demais de Simuliini.

Wygodzinsky \& Coscarón (1973) fazendo a revisão dos simulí́deos (Prosimuliini) nas Américas Central e do Sul apresentam uma chave de identificação para as pupas dos gêneros de Simuliidae, e como caracter primário para diferenciar Simulium (Simuliini) de todos os gêneros pertencentes a Prosimuliini (Mayacnephia, Tlalocomya, Cnesia, Gigantodax, Araucnephia, Araucnephioides, Cnesiamima, Paraustrosimulium e Lutzsimulium) escrevem:

"1. - Abdominal sterna VI and VII divided longitudinally along middle by membranous striate area (fig. $6 \mathrm{~L}$; 12C; 26), ........... 2 (indo para os gêneros de Prosimuliini) .

- - - Abdominal sterna VI and VII entired ............ Simulium".

Demonstram também, concordarem com a divisão de Prosimuliini e Simuliini, além de outros caracteres pupais, pela presença ou ausência de áreas membranosas estriadas na região ventral do abdome pupal.

Com base nas observaçōes sobre as áreas estriadas, penso que os conceitos para as pupas, pelo menos na região Neotropical (por não ter examinado material de outras regiões), devem ser reorganizados.

Proponho, primariamente, uma nova apresentação :

1. - Tanto Simuliini como Prosimuliini podendo apresentar ganchos nas áreas membranosas laterais aos esternitos VI-VII, sendo que estes estão separados das placas esternais por áreas membranosas estriadas longitudinais (Fig. 1A, B, C e D);

2. - Simuliini : Esternitos e tergitos abdominais apresentando fraca esclerotização; Com os esternitos V-VII e algumas vezes o VIII, divididos longitudinalmente por áreas membranosas estriadas medianas (Fig. 1A e B); 

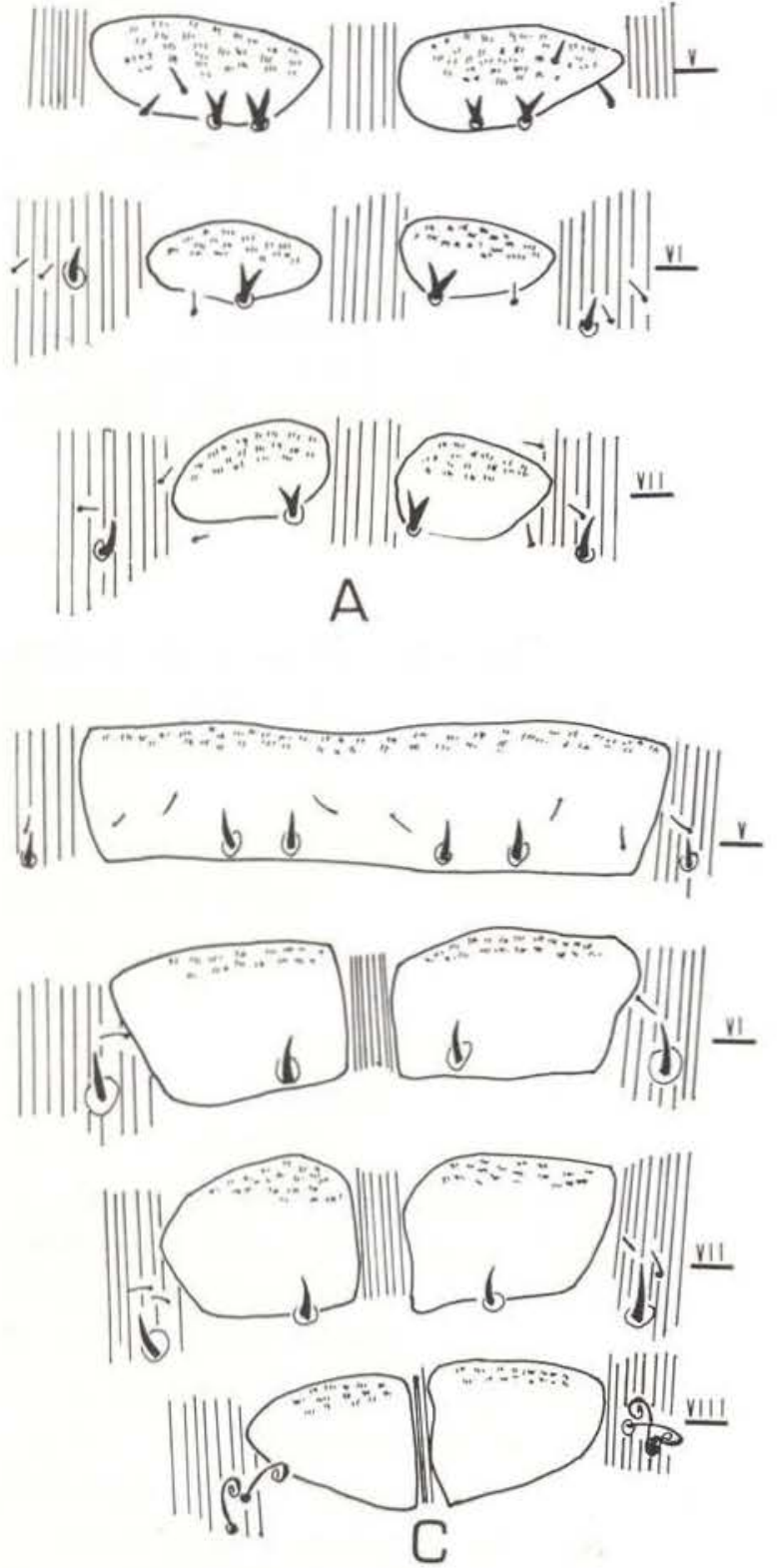
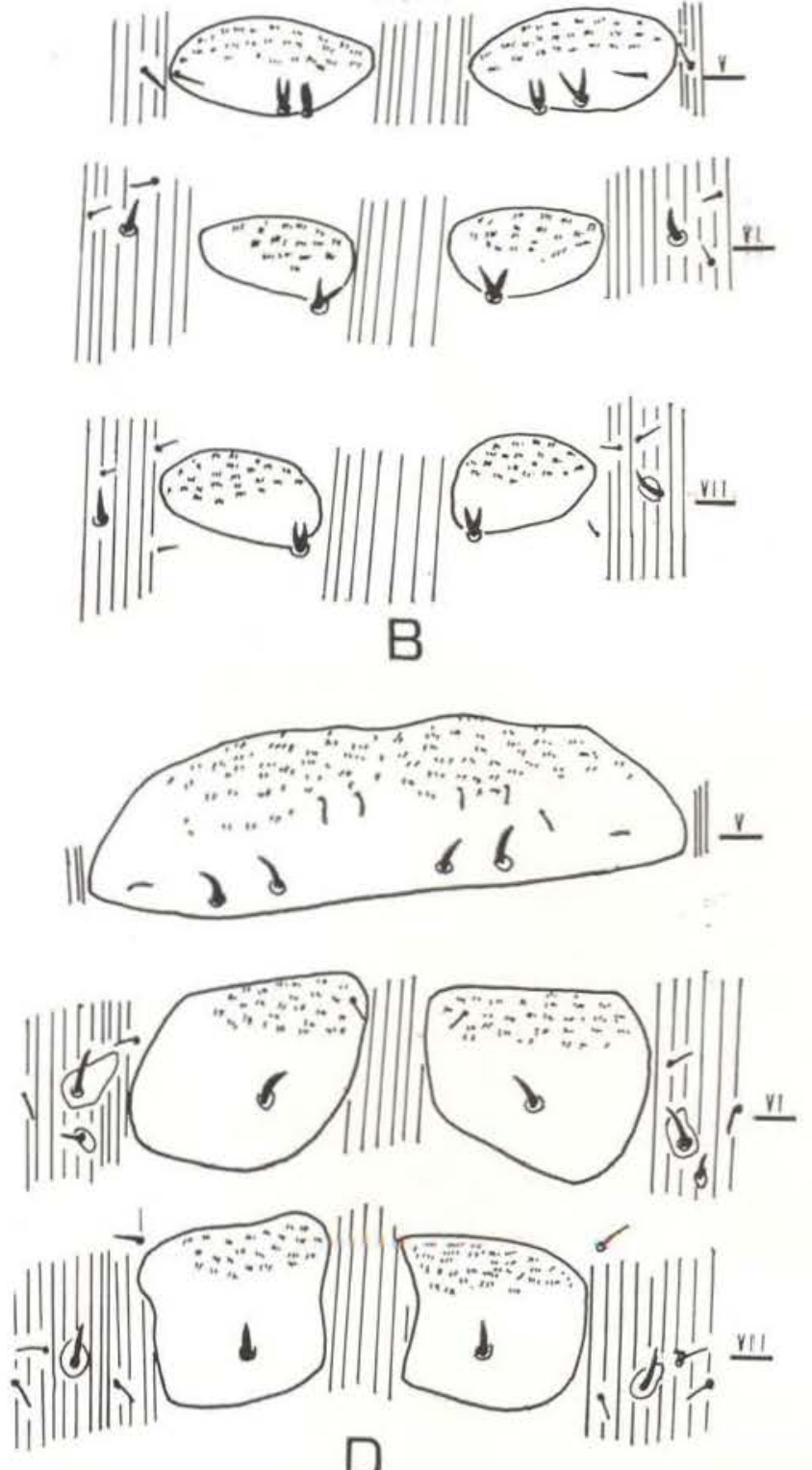

Fig. 1 - Aspectos da região ventral do abdome das pupas (esternitos V, VI, VII, VIII) de: (A) Simulium fulvinotum, (B) Simulium spinibranchium, (C) Lutzsimulium simplicicolor $n$. comb., (D) Paraustrosimulium anthracinum.

3. - Prosimuliini: Esternitos e tergitos abdominais apresentando acentuada esclerotização; Com áreas estriadas membranosas longitudinais, medianamente, apenas nos esternitos VI-VII e algumas vezes também no VIII (Fig. 1C, D).

MaTertal EXAminado

Simulium fulvinotum, Simulium perflavum, Simulium spinibranchium, Simu- lium wolffhuegelli, Simulium orbitale, Simulium goeldii, Simulium pruinosum, Paraustrosimulium anthracinum, Lutzsimulium pernigrum, Lutzsimulium hirticosta, Lutzsimulium simplicicolor $\mathbf{n}$. comb., Gigantodax wrighti.

\section{Agradecimentos}

Agradeço ao Dr. Sixto Coscarón, Museu de La Plata-Argentina, pelas observações e críticas sobre o trabalho. 


\section{SUMMARY}

New changes are proposed for the tribes Simuliin and Prosimuliini to those Crosskey (1969) and Wygodzinsky \& Coscarón (1973) based on laboratory observation of the abdomen of pupae (some neotropical species) that were not treated with the "clarifier-cleaner", $\mathrm{KOH}$. These changes would be: Simuliini - with median longitudinal striate membranous area on the sternites V-VII and sometimes VIII; Prosimuliini - with median longitudinal striate membranous area on the sternites VI-VII and sometimes also on the VIII.

\section{BIBLIOGRAFIA}

Crosskey, R.W.

1969 - A re-classification of the Simuliidae (Dip. tera) of Africa and its islands. Bull. Bri- tish. Mus. (Nat. Hist.) Ent., suppl., 14. pp. 1-195, 331 figs, 11 maps, 1 pl.

SNODGRASS, R.E.

1935 - Principles of insect Morphology, (reprinted), ix $+667 \mathrm{pp}$. Tata McGraw-Hill Publishing Company Ltd., New Delhi, India.

WYGODZINSKY, P. \& COSCARón, S.

1973 - A review of the Mesoamerican and South American black flies of the tribe Prosimuliini (Simuliinae, Diptera). Bull. Amer. Mus. Nat. Hist., 151: 129-200.

(Aceito para publicação em 16/07/79) 